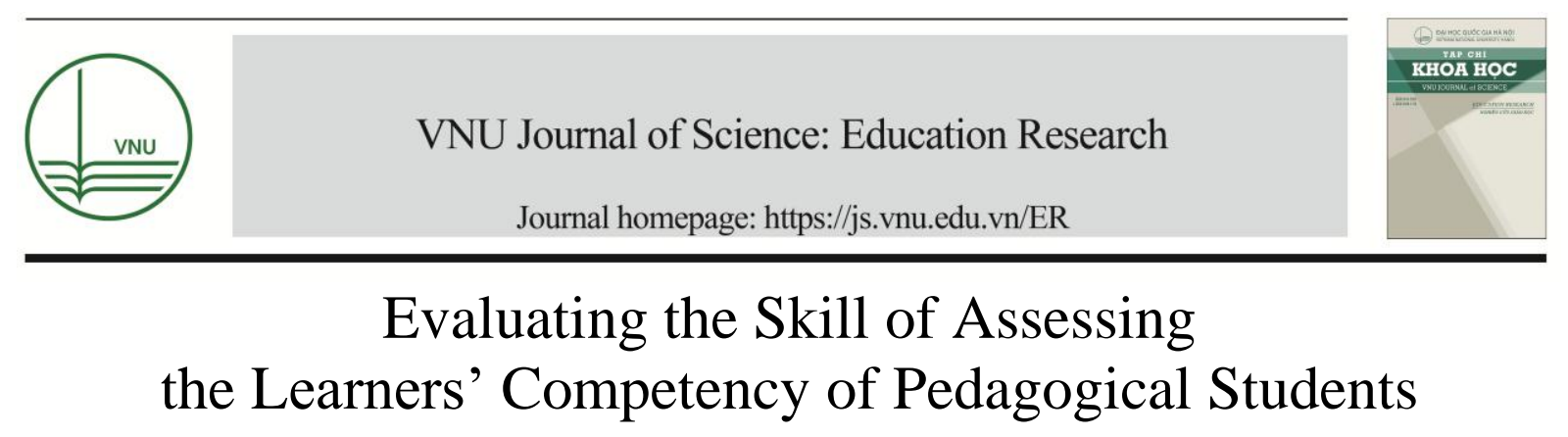

\author{
Nguyen Thi Viet Nga* \\ Institute for Pedagogical Research, Hanoi Pedagogical University 2, \\ Xuan Hoa, Phuc Yen, Vinh Phuc, Vietnam
}

Received 08 October 2018

Revised 20 October 2018; Accepted 12 December 2018

\begin{abstract}
Competency assessment skill is one of the basic teaching skills. Therefore, it is necessary for evaluating competency assessment skills of pedagogical students. The point is not only about how many teaching skills the students have had but also about the delicacy and flexibility between component skills of their general skills. In this article, we study theories of competency assessment skills in order to propose surveys evaluating the skills component of learners. Simultaneously, we are proposing general evaluation criteria for learners' competency assessment skills. The results from these surveys, conclusion and implication will be useful recommendation for lecturers and students to adjust their teaching and learning processes.
\end{abstract}

Keywords: Competency assessment skills, criteria form, scoring guidelines form.

\section{Rationale of the study}

From the 1980s there was "a revolution" on assessment in education. Instead of focusing mainly on summative assessment, it focuses more widely on learner performance. Therefore, there are forms of assessment such as formative assessment, authentic assessment and alternative assessment. Competency assessment involves a broad approach to measure learners' knowledge, skill and attitude, which reflect present changes of competency-based educational programs. These evaluation activities focus on necessary abilities for students to succeed in the future and on what

\footnotetext{
*Tel.: 84-984240449.

Email: nguyenvietnga86@gmail.com

https://doi.org/10.25073/2588-1159/vnuer.4177
}

students can do using the learned knowledge. According to Leenpil (2011) [1], competency assessment is to evaluate knowledge, skill and attitude of learners in a meaningful context.

While standardized scale in the competency assessment is based on competency development of learners, so the competency assessment focuses primarily on assessing learners' progress. In addition, students of the same age, learning the same education program but can achieve different levels of competencies. This cannot be done with the assessment of singular unit of knowledge and skills [2].

In the structure of competency evaluation for high school students, the tools usually are used as a system of tasks scaling: from easy to difficult, or from simple to complicated task activities of a field to measure any subject's 
competency development. Tasks for learners should be linked to the context in practice.

Characteristically, there is no conflict between competency evaluation and knowledge and skill evaluation. Competency evaluation is considered to be the higher level of skill development in comparison with knowledge and skill evaluation. Knowledge and skill evaluation is usually applied in a single subject, so it is detailed and specific [3]. At the same time, competency assessment can assess the synthesis of knowledge and skills in many subjects, thereby assessing the overall personality structure of students [3]. In order to evaluate certain abilities, practical opportunities should be given for students to resolve. Then, students must use their knowledge and skills learned at school and self-gathered experiences out of school (from family, community and society) to solve problems.

\section{Theories of competency assessment}

Nguyen Cong Khanh, Phan Thi Thanh Hoi, etc, suggested many groups of evaluation skills. According to Khanh Nguyen Cong [4], necessary skills to assess learners' competency include (1) developing an assessment plan, (2) selecting and designing assessment tools, (3) piloting and revising assessment tools, (4) assessing, (5) processing and analyzing data, (6) writing reports to explain and evaluate the result. Hoi Phan Thi Thanh [3] suggests a threephase assessment procedure - (1) preparing the content for assessment, (2) Conducting the assessment and analyzing the result, (3) making a decision to revise. Corresponding to these phases are the necessary skills to train the pedagogical students in assessing learners. The results of their studies show the focus on specifications and procedures of evaluation. Summarizing the above-mentioned studies, we may group these evaluation skills such as: evaluation activities preparation, testing design, evaluation process, analyzing and interpreting skills, and giving feedbacks. However, the group of evaluation process skill need to be conducted in the real context. Meanwhile, at our university we do not have the suitable conditions to train students on this skill group which is not concluded in the report.

There are some examples of skill structure that we provide to competency assessment skills evaluation in teaching process.

- Skills for preparation of the assessment activities

Preparing for the assessment activities means answering the following questions: What is the purpose of assessment? Who are responsible for conducting the assessment and using the results? What information should be collected? How can the information be collected and processed? What are the data collection tools? What learning activities are conducted to collect data? What is the timing, duration and order of assessment? What are the conditions for assessment? Therefore, the structure of this skills group is presented in Table 1:

Table 1. Structure of the skills for preparation of the assessment activities

\begin{tabular}{ll}
\hline Skills component & Description \\
\hline $\begin{array}{l}\text { Assessment planning } \\
\text { skills }\end{array}$ & $\begin{array}{l}\text { - Identify the objective of the evaluation } \\
\text { - Design evaluation procedures (the content, objects, the information to be collected } \\
\text { and processed, time, number and condition assessment) }\end{array}$ \\
$\begin{array}{l}\text { Determining skill of } \\
\text { - Identify opportunities for Ss' learning }\end{array}$ & $\begin{array}{l}\text { - Write behavior index (through the process of the implementation of skills) } \\
\text { behavior index to be }\end{array}$ \\
$\begin{array}{l}\text { evaluated Identify the most important behavior index } \\
\text { Building rubric skills } \\
\text { for scientific literacy }\end{array}$ & $\begin{array}{l}\text { - Select and use available scales or integrate multiple scales, or design new scale } \\
\text { consistent with the evaluation objective } \\
\text { - Design evaluation criteria table }\end{array}$ \\
\hline
\end{tabular}


- Skills on designing tests (Table 2)

- Skills on data analyzing, processing and interpreting (Table 3)
This skills group requires the use of data processing methods and identifies the impacts and causes of the phenomenon.

Table 2. Structure of skills in designing tests

\begin{tabular}{|c|c|}
\hline kills component & Description \\
\hline $\begin{array}{ll}\text { Test } & \text { matrix } \\
\text { development }\end{array}$ & $\begin{array}{l}\text { - Draw matrix details (form of exam, test form and needed awareness levels) } \\
\text { - Determination of the proportion corresponding to the content and level of Ss' } \\
\text { awareness }\end{array}$ \\
\hline $\begin{array}{l}\text { Competency } \\
\text { assessment questions } \\
\text { building }\end{array}$ & $\begin{array}{l}\text { - Determination of content, target of competency assessment suitable to assessed objects } \\
\text { - Compiling leading information segments and the focus of assessment } \\
\text { - Based on the target verb to determine the extent necessary to achieve } \\
\text { - Question assessment levels should be achieved and code answers } \\
\text { - Check the value of targeted questions to edit }\end{array}$ \\
\hline Test finalizing & $\begin{array}{l}\text { - Prospect the difficulty of the questions in the test } \\
\text { - Evaluate the quality of test and improve }\end{array}$ \\
\hline
\end{tabular}

Table 3. Structure of skills on data analyzing, processing and interpreting

\begin{tabular}{ll}
\hline Skills component & Description \\
\hline $\begin{array}{l}\text { Using the method } \\
\text { information processing }\end{array}$ & $\begin{array}{l}\text { - Use qualitative information criteria table } \\
\text { - Using mathematical formulas or quantitative processing software to evaluate } \\
\text { the quantitative information }\end{array}$ \\
$\begin{array}{l}\text { Data interpretation } \\
\text { - From the obtained data, give the assessment results of the Ss } \\
\text { - Identify the impacts and causes of results } \\
\text { - Interpretation of the Ss' level of development }\end{array}$ \\
\hline
\end{tabular}

- Skills on giving feedback include publishing results and making decisions for next steps.

Table 4. Structure on giving feedback skills

\begin{tabular}{|c|c|}
\hline Skills component & Description \\
\hline Transfer assessment results & - Identify the purpose and time of reporting \\
\hline $\begin{array}{l}\text { information to related } \\
\text { objects }\end{array}$ & $\begin{array}{l}\text { - Interpretation of report content } \\
\text { - Presentation of report language }\end{array}$ \\
\hline $\begin{array}{l}\text { Use the evaluation results } \\
\text { to adjust the teaching } \\
\text { process }\end{array}$ & $\begin{array}{l}\text { - Planning of pedagogical intervention of the teacher } \\
\text { - Guiding Ss how to plan to improve their achievement } \\
\text { - Make recommendations for parents }\end{array}$ \\
\hline
\end{tabular}

As shown in four tables above, competency assessment consists of many component skills which are logically related. In fact, these skills have not been paid enough attention at our university when it comes to teacher education. We focus more on training them how to design questions and answers. It can be said that this system of skills allows lecturers to identify the shortcomings in the training process.
3. Developing a set of criteria of skills component for competency assessment skills

There are now some popular models in the world for the development of thinking, abilities, capabilities that have been developed and are being applied. These include Bloom's Taxonomy (6 level: remember, understand, apply, analyze, evaluate, create), Dreyfus's five-stage modeling (Novice, advanced beginner, competent, proficient, expert), Biggs 
and Collis's learning outcomes model or SOLO (In the SOLO model, a student's learning outcome may be understanding at any one of five levels of complexity: no idea, one idea, loose ideas, connected ideas, extended ideas), etc. In these scales, Dreyfus's scales (table 5) are commonly used for skill assessments. In this study, we based on the Dreyfus scale to evaluate scoring guides.

Table 5. Dreyfus's Model of Skill Acquisition

\begin{tabular}{ll}
\hline Level & Description \\
\hline $\begin{array}{l}\text { 1. Novice } \\
\text { 2. Advanced } \\
\text { beginner }\end{array}$ & $\begin{array}{l}\text { Have insufficient knowledge, access to tasks mechanically and need supervision to } \\
\text { complete them. } \\
\text { Have an understanding of tasks, tend to view action as a series of steps, can accomplish simple } \\
\text { tasks unattended. }\end{array}$ \\
3ave a good understanding of tasks and background, analyse actions not holistically, can \\
accomplish tasks independently with an acceptable standard, although there may be a lack \\
of screening.
\end{tabular}

Building a scale of competency assessment skills, we use a four-level development path because students are unable to achieve the 5 th level (expert) in Dreyfus Model. In each level of the scale, we determine the proficiency upon the achievement level of skills component.

The scoring guide should show the score obtained for the skill and the criteria for the division of the levels. Scores of skills are calculated by the average of the behavioral indicators (weight dependent) [5].
A form of scoring guidelines is presented in Table 6, in which level 1: 0-2.5 points, level 2: 2.6-5 points, level 3: 5.1-7.5 points, level 4: 7.6-10 points. It is important to note that the interpretation of each level is applied in this research only.

Based on the expert method and the correlation coefficient analysis in the corresponding behavioral and affective behavior surveys, we have developed sets of criteria as follows.

Table 6. Scale of skill development in scoring guidelines form

\begin{tabular}{ll}
\hline Level (point/10) & Indicator \\
\hline Novice $(0-2,5$ points $)$ & Do not perform any steps or perform them incorrectly \\
2. Advanced beginner $(2,6-5$ points $)$ & Perform steps under teacher's detailed instructions \\
Competent $(5,1-7,5$ points $)$ & Perform steps more skillfully and more correctly without detailed \\
4. Proficient $(7,6-10$ points $)$ & instructions, but still make minor mistakes. \\
\hline
\end{tabular}

\subsection{Assessment criteria of assessment} planning skill

Evaluation of this skill is based on behaviors (with component scores) and the description is as follows.

- Identify assessment objectives (2 points)

+ L1. Can't identify assessment objectives or identify assessment objectives incorrectly
+ L2. Indicate assessment objectives, but not sufficiently or too general or inaccurately

+ L3. Identify assessment objectives, but sometimes inaccurately or unclearly

+ L4. Identify assessment objectives fully and clearly

- Establish assessment procedures (Time, duration, content, subjects, methods of 
assessment, information to be collected and processed) (5 points)

+ L1. Can't list all assessment procedures and some procedures are not fully identified

+ L2. Can list necessary procedures in S assessment including timing, time allowance, content, subjects, methods of assessment, information to be collected and processed; but can't order jobs to be done correctly, or mention inconsistent procedures, or mention consistent but incorrect procedures.

+ L3. Can establish assessment procedures that follow $\mathrm{S}$ assessment procedures, the procedures are consistent. There are still some minor mistakes or the procedures are not fully mentioned.

+ L4. Establish assessment procedures in assessing S clearly and consistently

- Identify learning opportunities for students (3 points)

+ L1. Can't design learning activities that match assessment objectives

+ L2. Can design learning activities, but not logically

+ L3. Can design necessary learning activities for students under teachers' instructions

+ L4. Can design necessary learning activities for students without teachers' instructions

In this form, establishing assessment procedures is considered the most important skill. That is the reason why this skill accounts for the highest point. However, students often fail to fulfill a large number of requirements in this area, most of them gain level 2.

3.2. Assessment criteria of identifying behavioral index of assessed competency skill

Evaluation of this skill is based on behaviors (with component scores) and the description is as follows.

- Know how to construct behavioral index (6 points):

+ L1. Can't construct behavioral indexes or construct behavioral indexes incorrectly
+ L2. Construct behavioral indexes using unclear language

+ L3. Construct required behavioral indexes, but need teachers' suggestions

+ L4. Construct behavioral indexes correctly for all skills/ competency without teachers' suggestions

- Focus on most important behavioral indexes (4 points)

$+\mathrm{L} 1$. Behavioral indexes are not subdivided at different levels of importance

$+\mathrm{L} 2$. Behavioral indexes are not subdivided at different levels of importance under T's instructions, but not fully and clearly

+ L3. Behavioral indexes are not subdivided at different levels of importance more clearly and correctly without T's constructions, but not fully and clearly. However, there are still some missing behaviors

+ L4. All behavioral indexes of different skills/competency are mentioned and subdivided at different levels of importance

\subsection{Assessment criteria of competency assessment rubric building skill}

Evaluation of this skill is based on behaviors (with component scores) and the description is as follows.

- Use either a built-in scale or combine different scales, or develop a new scale (5 points)

$+\mathrm{L} 1$. Can list a number of scales, but can use them

+ L2. Use either a built-in scale or combine different scales, but can't develop a new scale or use scales ineffectively

+ L3. Use scales more correctly without detailed instructions, but not effectively

+ L4. Can use all scales, analyze the strengths and weaknesses of the scales to develop a new scale for all assessed skills

- Develop skill assessment rubric (5 points)

+ L1. Can't develop skill assessment rubric, or develop skill assessment rubric with some missing criteria

+ L2. Develop skill assessment rubric under T's instructions, but the criteria are not clear 
and consistent among different levels, language used is not clear.

+ L3. Develop clear skill assessment rubric without detailed instructions, but there are still some missing criteria

+ L4. Develop clear skill assessment rubric for all assessed skills

\subsection{Assessment criteria of test matrix developing skill}

Evaluation of this skill is based on behaviors (with component scores) and the description is as follows.

- Develop detailed test matrix (5 points)

+ L1. Can't mention necessary components in a test matrix

+ L2. Can develop a test matrix with components, but can't identify test contents and levels

+ L3. Can develop a test matrix with components, identify test contents and levels, but incorrectly

+ L4. Develop detailed test matrix with contents and levels for all assessed contents

- Assign proportion of the content and students' performance (5 points)

+ L1. Can't assign proportion of the content and students' performance

+ L2. Can set out rules to assign proportion of the content and students' performance, but apply the rules inconsistently

+ L3. Can set out rules to assign proportion of the content and students' performance under teacher's instructions

+ L4. Can set out rules to assign proportion of the content and students' performance skillfully

\subsection{Assessment criteria of competency} assessment question building skill

Evaluation of this skill is based on behaviors (with component scores) and the description is as follows.

- Determine assessment contents and objectives suitable to the assessed subject (1 point)

+ L1. Can determine contents and objectives as in competency structure
+ L2. Can determine contents and objectives as in competency structure, but they are not suitable for assessed subject

+ L3. Can determine suitable contents and objectives as in competency structure for assessed subject under teachers' instructions

+ L4. Determine suitable assessed contents and objectives according to competency structure for assessed subject without T's instructions

- Compile introductory information basing on focused contents and objectives to be assessed (3 points)

+ L1. Can't compile suitable introductory information

+ L2. Can find introductory information, but can't compile introductory information suitable for assessed objectives and contents

+ L3. Compile introductory information suitable for assessed objectives and contents under teachers' instructions

+ L4. Compile introductory information suitable for assessed objectives and contents without T's instructions

- Determine the achievement level of the competency basing on the verbs in the objectives ( 2 points)

+ L1. Can't determine learners' degree of achievement of the competency

+ L2. Can determine learners' degree of achievement of the competency, but make many mistakes

+ L3. Can determine learners' degree of achievement of the competency under T's instructions

+ L4. Can determine learners' degree of achievement of the competency without T's instructions

- Compile questions to assess the achievement level of the competency and encode responses ( 3 points)

+ L1. Compile questions and encode responses, or do them incorrectly

+ L2. Compile questions, but the questions are sometimes unsuitable for the degree of the assessed competency 
+ L3. Compile suitable questions, but the encoded responses can't cover all learners' answering ability

+ L4. Compile suitable questions and encode responses that cover all learners' answering ability

- Check the question value basing on the objectives for editing (1 point)

$+\mathrm{L} 1$. Can't check the question value

+ L2. Check the question value basing on the initial objectives, but make many mistakes

+ L3. Check the question value basing on the initial objectives, but need T's suggestions

+ L4. Be skillful in checking the question value and editing questions

Competency assessment questions building is the most critical and challenging skill in assessing competency. Therefore, behaviors are described with specific steps.

\subsection{Assessment criteria of test piloting and test completing skill}

Evaluation of this skill is based on behaviors (with component scores) and the description is as follows.

- Identify the difficulty level of test items (5 points)

+ L1. Can't identify the difficulty level of test items

+ L2. Know the formula to identify the difficulty level of test items, but make many mistakes

+ L3. Identify the difficulty level of test items accurately with both math formulas and support software, but make some minor mistakes when calculating or importingexporting data in the software

+ L4. Identify the difficulty level of test items accurately, skillfully with both math formulas and support software in all the assessment content

- Evaluate test quality and improve tests (5 points)

+ L1. Can't evaluate test quality

$+\mathrm{L} 2$. Be able to evaluate test quality under teacher's instruction, but frequently base on subjective viewpoints
+ L3. Evaluate test quality more accurately without teacher's instruction, but sometimes base on subjective viewpoints

+ L4. Evaluate test quality accurately in different conditions and circumstances based on statistics

\subsection{Assessment criteria of data processing skill}

Evaluation of this skill is based on behaviors (with component scores) and the description is as follows.

- Use assessment criteria chart (5 points)

+ L1. Can't use the assessment criteria chart properly, or use it but can't identify criteria

$+\mathrm{L} 2$. Be able to use the assessment criteria chart under teacher's instruction, but frequently make mistakes between criteria description and students' behavior

$+\mathrm{L} 3$. Be able to use the assessment criteria chart, but still make minor mistakes

+ L4. Use the assessment criteria chart skillfully, combine assessment criteria charts to make general evaluation

- Use software to analyse qualitative data (5 points)

+ L1. Can't use assessment software

+ L2. Be able to import data, read data output result in the software under teacher's instruction, but still make many mistakes

+ L3. Import and export data skillfully in assessment activities, but sometimes make mistakes

+ L4. Use the software skillfully and flexibly in all assessment cases

\subsection{Assessment criteria of data analyzing skill}

Evaluation of this skill is based on behaviors (with component scores) and the description is as follows.

- Make statistics-based evaluation
(4 points)
$\quad+$ L1. Collect data but can't interpret
students' test result
$\quad+\mathrm{L} 2$. Be able to interpret students' test
result under teacher's instruction, but with
little accuracy


+ L3. Interpret students' test result, but sometimes inaccurately

+ L4. Interpret students' test result accurately and skillfully

- Identify factors and causes of evaluation result (3 points)

+ L1. Can't identify factors and causes of evaluation result (from students, teachers, family)

$+\mathrm{L} 2$. Be able to identify some factors and causes under teacher's instruction but still make many mistakes

+ L3. Identify some factors and causes but inadequately or without absolute accuracy

+ L4. Quickly identify some factors and causes in all cases

- Explain students' development level (3 points)

+ L1. Can't explain students' develop ment

+ L2. Under teacher's instruction, be able to explain students' development mechanically, with many mistakes

+ L3. Explain students' development more accurately, but sometimes make mistakes

+ L4. Quickly make theory-based explanation on students' development in all assessment activities

This is a new skill for students. Most of them fail to complete this phase, if possible, they can achieve level 1 only. Therefore, this table is meaningful for students to develop their competency assessment skill.

3.9. Assessment criteria of disseminating assessment result to relevant stakeholders skill

Evaluation of this skill is based on behaviors (with component scores) and the description is as follows.

- Purpose and timing of report (3 points)

+ L1. Don't understand the purpose and timing of report

+ L2. Under teacher's instruction, be able to indicate the purpose and timing of report, but mechanically and make many mistakes

+ L3. Identify the purpose and timing of report skillfully, but sometimes make mistakes

+ L4. Quickly indicate the purpose and identify suitable timing of report
- Report content (4 points)

+ L1. Can't identify report content

$+\mathrm{L} 2$. Be able to identify report content, but don't know the report outline

$+\mathrm{L} 3$. Be able to write report, but not really adequately, precisely and concisely

+ L4. Quickly present report content which is suitable to its purpose and timing

- Report language (3 points)

+ L1. Report language is difficult to understand, not explicit, accurate

+ L2. Under teacher's instruction, report is more reader-friendly and easier to understand, but still wordy and not accurate

+ L3. Report is reader-friendly and easy to understand, concise but still sometimes wordy and ambiguous

+ L4. Report is written academically, precisely and explicitly

It is a common belief among students that they just need to inform test results to the learners. That is why students often get level 1 or 2 for this skill. Therefore, this rubric is essential in their assessment and selfassessment, helping students to realize their weaknesses so that they can improve later.

3.10. Assessment criteria of using assessment result to improve instruction skill

Evaluation of this skill is based on behaviors (with component scores) and the description is as follows.

- Teacher intervention planning (4 points)

+ L1. Don't know what to do after evaluating students

+ L2. Under teacher's instruction, be able to make some pedagogical intervention for student's competency development after assessment, but incomplete and inaccurate

+ L3. Suggest follow-up actions for teachers in the teaching process for student's competency development. These actions are often meaningful and necessary for the teaching process, but sometimes they are also inaccurate or unnecessary

+ L4. Quickly set up pedagogical intervention plans that are accurate and 
necessary for student's competency development

- Instructs students to make a plan to improve their performance ( 3 points)

+ L1. Can't instruct students to make a plan to improve their performance

+ L2. Be able to instruct students to improve their academic performance but it is not thorough, not specific or inaccurate, making students not achieve their goals.

+ L3. Instruct students make a plan to improve their performance in a clear, explicit, easy-to-implement manner, but sometimes inaccurate

+ L4. Always instruct students make a plan to improve their performance in a clear, explicit, easy-to-implement manner

- Make recommendations for students' parents (3 points)
+ L1. Can't make recommendations for students' parents

$+\mathrm{L} 2$. Be able to make recommendations for students' parents, but they are too general, ineffective or mechanical, inaccurate

+ L3. Make accurate and flexible recommendations for students' parents, but sometimes make minor mistakes

+ L4. Make accurate and effective recommendations for students' parents

\section{Design a scale to assess competency assessment skill}

By expert methods, and based on the difficulty of component skills and the level of proficiency of synthetic skills, we have experimented with surveying and modifying these levels. The results are as follows.

Table 7. Assessment form of achievement level of learner competency assessment skills

\begin{tabular}{|c|c|c|}
\hline Skills & Assessment contents & Points \\
\hline Develop an assessment plan & $\begin{array}{l}\text { - Identify clear and accurate assessment objectives } \\
\text { - Design clear and consistent procedures in the assessment process } \\
\text { - Identify the learning opportunities of the students after the } \\
\text { assessment }\end{array}$ & 0,5 \\
\hline $\begin{array}{l}\text { Identify behavioral index of } \\
\text { the competency to be } \\
\text { assessed }\end{array}$ & $\begin{array}{l}\text { Identify important behavioral index and describe behavioral index } \\
\text { of each competency in a clear, accurate manner }\end{array}$ & 0,5 \\
\hline Develop assessment rubric & Develop a clear, accurate assessment rubric skillfully & 1 \\
\hline Develop test matrix & Develop detailed test matrix which fits evaluation objectives & 2 \\
\hline $\begin{array}{l}\text { Develop competency } \\
\text { assessment questions }\end{array}$ & $\begin{array}{l}\text { Test items can assess students' competency and fit the evaluation } \\
\text { objective, content and methods }\end{array}$ & 3 \\
\hline Test pilot and test completion & Pilot tests and evaluate test quality to improve tests & 2 \\
\hline $\begin{array}{l}\text { Apply data processing } \\
\text { methods }\end{array}$ & Use assessment tools skillfully (criteria form, support software) & 0,5 \\
\hline Interpret collected data & Interpret data clearly and accurately & 1 \\
\hline $\begin{array}{l}\text { Disseminate assessment result } \\
\text { to relevant stakeholders }\end{array}$ & $\begin{array}{l}\text { Disseminate assessment result at the right time, provide clear, accurate } \\
\text { information }\end{array}$ & 0,5 \\
\hline $\begin{array}{l}\text { Use assessment result to } \\
\text { improve instruction }\end{array}$ & $\begin{array}{l}\text { Use assessment result to make a clear, accurate, feasible plan for teachers } \\
\text { and students }\end{array}$ & 1 \\
\hline
\end{tabular}

Table 7 helps lecturers to determine the score for students' skill of assessing the learner's competency. Table 6 helps lecturers to identify students' achievement level of this skill. As a result, they could figure out students' weaknesses that need more work in order to enhance students' skills.
The assessment forms in part 3 can be used to train pedagogical students in assessment skills. These forms help to clarify which skills students lack and at which level they gain. When students understand component skills, "Assessment form of achievement level of learner competency assessment skills" (Table 7) 
is used to assess them. This would help the process of identifying strengths and weaknesses of students in component skills and their ability to integrate them.

\section{Conclusion}

This research synthesizes the theories of competency assessments and the structure of competency assessment skills. Thereby, a tool kit of 10 scoring guidelines of assessment component skills is introduced. Pedagogical lecturers can use them as a base for developing training content and assessing the progress of these skills for students. In addition, pedagogical students themselves may also use these guidelines as criteria for developing self-study plans to develop competence assessment skills.

Through the experiment process, and then based on the results for editing, we have built a scale for evaluating the skill of learner competency assessment. This will be a tool for pedagogical lecturers to use in their teaching process in order to train and evaluate students more favorably.

\section{Acknowledgments}

This research is funded by the Science and Technology Fund of Hanoi Pedagogical University 2. The subject code is: C.2017-18- 08.

\section{References}

[1] Ron Cammaert - Secondary Education Development program (2013), Capacity - Based Assessment, Hanoi.

[2] Dang Vu Hoat, Ha Thi Duc (1990), Problems of examining and evaluating knowledge in the history of education and school, Publisher of Hanoi Pedagogic University, Hanoi.

[3] Le Dinh Trung, Phan Thi Thanh Hoi (2015), Teaching oriented towards the formation and development of learners capacity in upper secondary schools, Publisher of Hanoi Pedagogic University, Hanoi.

[4] Nguyen Cong Khanh, Dao Thi Oanh, Le My Dung (2014), Testing and assessment in education, HNUE publisher, Hanoi.

[5] Giselleo. Martin-kniep (translated by Le Van Canh), Eight innovations to become a good teacher, Vietnam Education publisher, HN, 2011.

illiam D.Shafer, Assessment skills for school counselors, U.S. Department of Education, OERI, 1995. 